\title{
Lendo histórias em família: influências sobre o vocabulário infantil e desempenho em leitura e escrita
}

\author{
Acácia Aparecida Angeli dos Santos \\ Universidade São Francisco \\ Maria Cristina Rodrigues Azevedo Joly \\ Universidade São Francisco
}

\begin{abstract}
Resumo
Os objetivos desta pesquisa foram: verificar a influência da leitura em família sobre o vocabulário infantil, o desempenho escolar de crianças e padrões de interação familiar. Os sujeitos da pesquisa foram 38 crianças, freqüentando duas pré-escolas (particular e pública) e seus pais que participam semanalmente de um programa voltado para atividades de leitura. Realizou-se a avaliação inicial e final através de: questionário informativo respondido pelos pais; o Teste Metropolitano de Prontidão (TMP) e o Teste de Competência em Leitura (ITPA) para os grupos experimental (GE) e de controle (GC). Os resultados revelaram melhora no desempenho geral dos sujeitos dos grupos experimentais e mudanças nas atitudes frente à leitura e freqüência à biblioteca.
\end{abstract}

Palavras-Chave: Leitura em Família, Contar histórias, leitura e escrita

\section{Family reading: influence in children vocabulary and reading-writing performance}

\section{Summary}

This research goals were: identify the family reading influence in the vocabulary,in the children's school performance, and in the family interation patterns. The subjects were 36 children, frequenting two pre-schools (private and public). Their parents participated weekly in a reading programo The initial and final assess were realized with: informative questionary answered by the parents; the Readiness Metropolitan Test (TMP) and the Reading Competence Test (ITPA) to the experimental (GE) and control (GC) groups. The results showed improvement in the development of the experimental group subjects, changes in the attitude toward the reading and library frequence

Keywords: family reading, storytelling, reading and writing

\section{Introdução}

Nos últimos anos, tem havido grande interesse dos estudiosos de diversas áreas pela influência da prática da leitura de histórias infantis sobre a aquisição da leitura e escrita na criança, bem como sobre o vocabulário infantil. A população frequentemente enfocada tem sido famílias de pré-escolares norte-americanos, de origem anglosaxônica. A maior parte destes estudos visa explorar as diferenças no padrão de desempenho de crianças com backgrounds diversos (Snow, 1983; Teale, 1986; Dickinson e Smith, 1994)

Um estudo típico da questão foi elaborado por Philips e McNaughton (1990) com o objetivo de descrever a atividade de leitura entre pais e filhos de 3 e 4 anos pertencentes a dez famílias da classe socio-econômica predominante na Nova Zelândia. Os resultados demonstraram que ler contos para as crianças é um evento freqüente entre as famílias estudadas e que em função disto, as

\footnotetext{
Participaram da pesquisa como colaboradora a Prof. Maria Carolina K. Pellegrini e como bolsistas de Iniciação Científica do CNPq, as acadêmicas de Psicologia/USF, Cibonei Nogueira Fuentes e Soemes H. Finazzi Carvalho
} 
crianças advindas dessas famílias neozelandezas apresentam conhecimentos de construção de significado de histórias ao iniciarem a etapa de escolarização.

Neste mesmo sentido, Combs e Beach (1994) consideram que o relato de histórias é essencial para a determinação da nossa visão da realidade. Os autores alertam para o fato de que, atualmente, a escola trabalha com crianças expostas a um mundo de constantes mudanças. Consideram assim, que o envolvimento da família se toma imprescindível como esteio para o currículo escolar, e que através do relato de histórias a família poderia fornecer este suporte necessário.

Outros autores como Feitelson e colaboradores (1993) realizaram estudos para avaliar os efeitos do "ouvir histórias" sobre os padrões lingüísticos de pré-escolares e relataram resultados bastante animadores. Através de uma pesquisa experimental, com crianças árabes, os autores verificaram que as do grupo experimental, submetidas a um programa de contos infantis apresentados pela professora, tiveram um desempenho superior às do grupo de controle, submetidas a um programa de melhoria de habilidades lingüísticas proposto pelo Ministério da Educação.

Os estudos sobre o assunto têm causado impacto sobre as práticas educativas, especialmente nos Estados Unidos, e tem gerado a organização de ações mais abrangentes, que incluem a divulgação de programas de parceria entre as escolas e famílias. Tais ações vêm apresentando resultados bastante promissores, que, comprovam múltiplos benefícios, tanto para a escola como para a família (Handel, 1992). Morrow e colaboradores (1994) têm-se preocupado em pesquisar e desenvolver programas para serem realizados com as famílias, visando a aquisição de competência em habilidades de leitura, escrita e cálculo pelas crianças através de atividades que possam ser realizadas entre pais e filhos em sua rotina diária.

Os estudos têm demonstrado que nos lares onde há leitura freqüente tanto dos pais quanto das crianças, diálogo, acesso fácil e freqüente a materiais de leitura e escrita e as crianças são reforçadas positivamente sobre o seu desempenho em atividades de letramento, observam-se efeitos positivos nas habilidades específicas de leitura e escrita.

No Brasil, dados interessantes sobre a questão foram obtidos com um estudo das representações sobre o comportamento de leitura de crianças, segundo a visão das mães (Santos, 1993). Por outro lado, tem havido várias propostas que visam a inserção de práticas pedagógicas incluindo a literatura infantil como atividade habitual. (Rockenback, 1990; Santos e Joly, 1994). É evidente no entanto, a necessidade de novos estudos que permitam um aprofundamento de alguns dos aspectos envolvidos.

A relevância da questão e a necessidade de maiores investigações sobre as variáveis envolvidas, foram os princípais fatores que motivaram esta pesquisa, proposta com o objetivo de: a) verificar a influência da leitura em família sobre o vocabulário infantil e o desempenho escolar de crianças, especialmente no que se refere à aquisição da leitura e escrita; b) avaliar seus efeitos sobre os hábitos de leitura da família e os padrões de interação familiar.

\section{Método}

Foi utilizado o método experimental, incluindo a comparação entre grupos (experimental e de controle) em situação de pré e pós-teste.

\section{Sujeitos/Situação}

Serviram como sujeitos da presente pesquisa 38 crianças pré-escolares de uma escola da rede 
particular e outra da rede pública, sendo 19 sujeitos do sexo feminino e 19 do masculino com idade média de 6 anos e 4 meses. Participaram também pais destas crianças, que voluntariamente se inscreveram no programa de leitura proposto.

\section{Material}

Foram utilizados os seguintes materiais: l-Questionário Informativo, visando obter a caracterização dos pais das crianças, padrões de interação familiar e atitudes das crianças frente leitura; 2- Teste Metropolitano de Prontidão (TMP)- Forma R; 3- Teste de Competência em leitura ITPA - (Moura e Saboya, 1981); 4- Livros de histórias infantis.

\section{Procedimento}

A pesquisa foi realizada em etapas, sendo a $1^{\mathrm{a}}$ a fase de avaliação do nível de prontidão dos sujeitos.Numa segunda etapa foi desenvolvido o Programa de Leitura, para os pais que voluntariamente se inscreveram, constando de 15 encontros de 1h, nos quais se apresentou noções gerais sobre leitura e se discutiu sobre a sua importância no contexto educacional e familiar. 
Quadro 1. Cronograma de atividades do Programa de Leitura com Pais

\begin{tabular}{|c|c|c|c|}
\hline & & CONTEÚDO & ESTRATÉGIAS \\
\hline $\begin{array}{c}1^{\circ} \text { Encontro } \\
03 / 05 / 95\end{array}$ & Apresentação do Programa & $\begin{array}{l}\text { QuestionárioMemórias } \\
\text { Leitura }\end{array}$ & Discussão em grupo \\
\hline $\begin{array}{l}2^{\circ} \text { Encontro } \\
10 / 05 / 95\end{array}$ & Vamos sonhar? & Contos de fadas & Usando vídeo \\
\hline $\begin{array}{c}3^{\circ} \text { Encontro } \\
17 / 05 / 95\end{array}$ & Texto:"Meu Amigo Livro" & Leitura & Discussão em grupo \\
\hline $\begin{array}{l}4^{\circ} \text { Encontro } \\
24 / 05 / 95\end{array}$ & $\begin{array}{l}\text { Aprendendo Novas } \\
\text { Informações }\end{array}$ & Informativo & Usando o Livro \\
\hline $\begin{array}{l}5^{\circ} \text { Encontro } \\
31 / 05 / 95\end{array}$ & $\begin{array}{l}\text { Texto "Jogar é Aprender a } \\
\text { Viver" }\end{array}$ & Atividades lúdicas & Discussão em Grupo \\
\hline $\begin{array}{c}6^{\circ} \text { Encontro } \\
07 / 06 / 95\end{array}$ & Uma Aventura & Aventura & Narrativa \\
\hline $\begin{array}{c}7^{\circ} \text { Encontro } \\
14 / 06 / 95\end{array}$ & Palestra & Informativo & Discussão em grupo \\
\hline $\begin{array}{c}8^{\circ} \text { Encontro } \\
21 / 06 / 95\end{array}$ & $\begin{array}{l}\text { Texto: "Pequenas Tarefas: } \\
\text { Grandes Negócios" }\end{array}$ & Atitudes infantis & Discussão em grupo \\
\hline $\begin{array}{c}9^{\circ} \text { Encontro } \\
16 / 08 / 95\end{array}$ & Texto & Situações familiares & Discussão em grupo \\
\hline $\begin{array}{c}10^{\circ} \text { Encontro } \\
23 / 08 / 95\end{array}$ & Vamos manter a tradição? & Folclore & Usando objetos variados \\
\hline $\begin{array}{l}11^{\circ} \text { Encontro } \\
30 / 08 / 95\end{array}$ & $\begin{array}{l}\text { Texto: "Os cuidados para a } \\
\text { criança não se perder" }\end{array}$ & Autonomia infantil & Discussão em grupo \\
\hline $\begin{array}{c}12^{\circ} \text { Encontro } \\
13 / 09 / 95\end{array}$ & $\begin{array}{l}\text { Pensando em situações } \\
\text {-problema }\end{array}$ & Solução de problemas & Dramatização \\
\hline $\begin{array}{c}13^{\circ} \text { Encontro } \\
20 / 09 / 95\end{array}$ & Palestra & $\begin{array}{l}\text { Tema: Problemas de } \\
\text { Aprendizagem nas } \\
\text { crianças }\end{array}$ & Expositiva -dialogada \\
\hline $\begin{array}{l}14^{\circ} \text { Encontro } \\
27 / 09 / 95\end{array}$ & $\begin{array}{l}\text { Vivendo- e sonhando } \\
\text { através de aventuras }\end{array}$ & Aventura & Criatividade \\
\hline $\begin{array}{c}15^{\circ} \text { Encontro } \\
04 / 10 / 95\end{array}$ & Término do programa & Questionário & Discussão em grupo \\
\hline
\end{tabular}

Durante os encontros foram utilizadas diferentes estratégias para se contar histórias,de acordo com o Quadro 1, bem como técnicas de dinâmica de grupo. Em cada encontro desenvolviam -se as seguintes atividades: 1- relato informal dos pais sobre as leituras em família, realizadas com as crianças, possibilitando a discussão dos seguintes aspectos: interação familiar; participação da criança; conteúdo do livro e estratégia utilizada; 2- apresentação da temática do encontro através de uma história usando-se, a cada vez, uma estratégia específica; 3- escolha de livros de história, pelos pais, na Biblioteca Escolar, considerando-se as mesmas características do livro utilizado no encontro anterior; 4- organização dos pais em pequenos grupos e aplicação de estratégia, já apresentada, ao conteúdo do livro escolhido; 5demonstração da estratégia pelos diferentes grupos para os demais participantes; 6- discussão geral entre os participantes e o coordenador;? - retirada 
de livros de história da biblioteca escolar para leitura em família.

No primeiro e no último encontro foi aplicado um questionário informativo e coletados depoimentos dos pais, possibilitando a avaliação de suas expectativas e aproveitamento em relação aos encontros.

Após o encerramento do Programa as crianças, de ambas as escolas, foram submetidas novamente ao Teste Metropolitano de Prontidão e Teste de Competência em Leitura, independentemente de seus pais terem ou não participado do mesmo.

\section{Resultados e discussão}

Os resultados obtidos na presente pesquisa revelaram que o programa de leitura desenvolvido com os pais de crianças pré-escolares da escola pública e particular pode ter possibilitado alterações em alguns aspectos significativos para a aquisição do hábito de ler, no desempenho escolar das crianças e nos padrões de interação familiar corroborando os estudos de Edwards (1960, 1994) e Handel (1992), dentre outros.

Os pais das crianças da escola pública apresentaram uma freqüência baixa de leitura, enquanto que os da escola particular podem ser considerados bons leitores.

Na escola particular, os pais são os que mais freqüentem ente lêem para seus filhos, destacando-se os avós com freqüência média para o grupo controle a nível de pré-teste e para os irmãos do grupo experimental que passaram de uma freqüência baixa de leitura no pré-teste para uma freqüência média no pós-teste. Isto revela que o programa pode ter modificado o hábito de leitura dos irmãos que passaram a estabelecer um novo tipo de interação com os sujeitos através da leitura de histórias.

Quanto à escola pública, os leitores para as crianças do grupo experimental são os pais, avós e tios, enquanto que para as do grupo controle a leitura de histórias é delegada à mãe. Não se observaram mudanças nesse padrão a nível de pós-teste. Este dado nos mostra que, apesar dessas crianças terem pais cuja freqüência de leitura é baixa, um possível déficit advindo desse fato é suprido pela presença de outros leitores na família (avós e tios).

Identificou-se que o estilo preferencial de histórias para os sujeitos da escola particular é o conto de fadas, sendo que a estratégia mais utilizada pelos pais para ler é usando o próprio livro. Para os sujeitos da escola pública, a preferência é pela aventura e as estratégias utilizadas pelos pais são a narrativa e a leitura do livro. Não ocorreram mudanças nesses aspectos a nível de pós-teste.

Pode-se verificar alterações nas atitudes dos sujeitos do grupo experimental a nível de pósteste em relação à leitura, conforme mostram as figuras 1 e 2.

Pode-se verificar que a solicitação da criança do grupo experimental de ambas as escolas para ouvir histórias e seu nível de compreensão das mesmas, segundo o relato de seus pais, sofreram modificações após o programa de leitura. Na escola pública, há diferenças mais acentuadas na pontuação desses aspectos. Os pais da escola particular relataram que observaram diferenças no padrão lingüístico de seus filhos, quanto à: aumento de vocabulário, maior capacidade de reproduzir e aplicar a história, além de maior compreensão do conteúdo. Constataram também, que as crianças se tomaram mais ativas e participantes durante o relato da história, opinando e criticando sobre o tema e o enredo, vindo a confirmar as pesquisas (1993). 


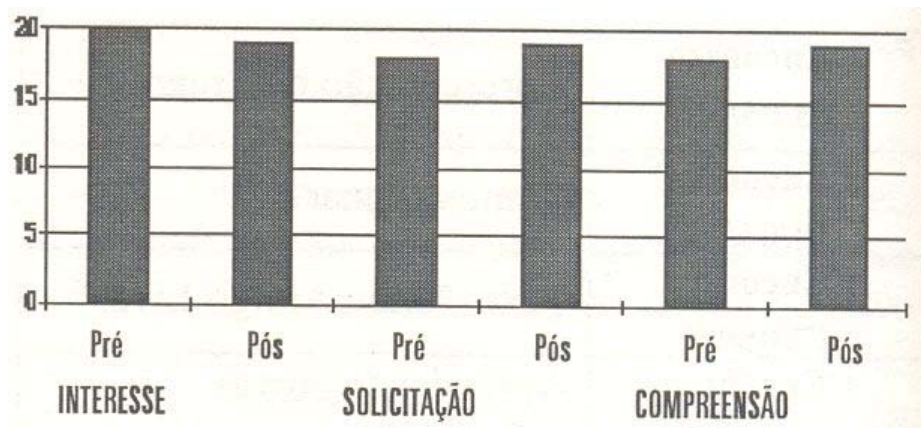

Figura 1. Pontuação atribuída aos sujeitos do grupo experimental (GE) da escola particular relativa à sua atitude frente a leitura a nível de pré e pós testes no programa de leitura

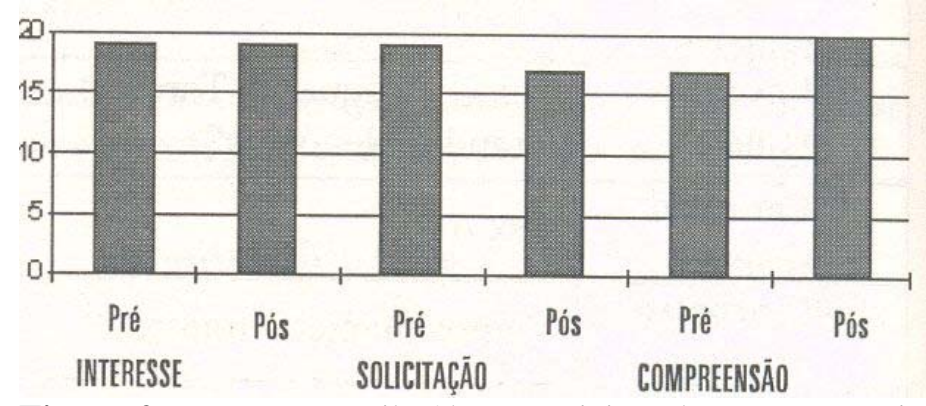

Figura 2. Pontuação atribuída aos sujeitos do grupo experimental (GE) da escola pública relativa à sua atitude frente a leitura a nível de pré e pós testes no programa de leitura

Associada à mudança de atitude dos sujeitos de ambas as escolas frente à leitura, identificouse alterações em relação ao acesso dos sujeitos à materiais diversificados de leitura e freqüência à biblioteca tanto pública quanto da escola, de acordo com os dados apresentados nas figuras 3 e 4.

Observa-se que houve uma diminuição do manuseio de materiais diversificados de leitura para um aumento da leitura de livros de histórias e acesso à biblioteca para os grupos experimentais das duas escolas, demonstrando o maior interesse dos sujeitos pela leitura e a instalação efetiva do hábito de ler.

Analisando-se o desempenho escolar dos sujeitos quanto à prontidão para a leitura e escrita, a Tabela 1 mostra a porcentagem média de respostas obtidas por grupo nas provas do Teste Metropolitano de Prontidão (TMP)

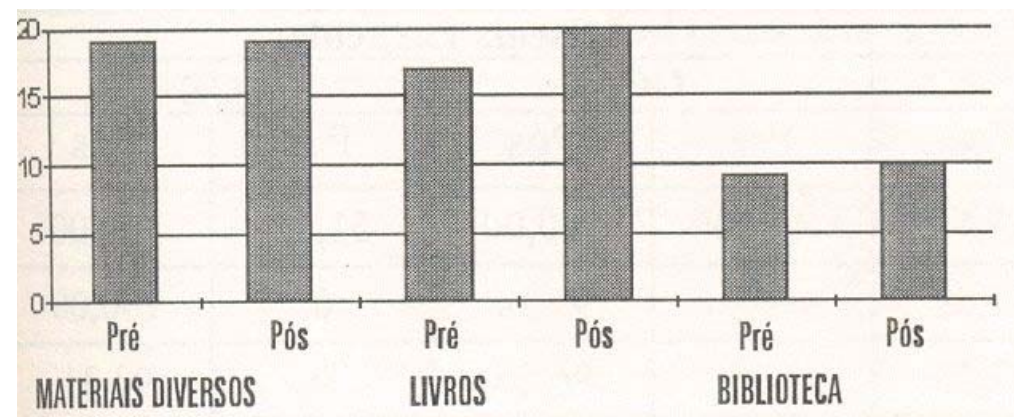

Figura 3. Pontuação atribuída aos sujeitos do grupo experimental (GE) da escola particular relativa ao seu acesso à leitura 


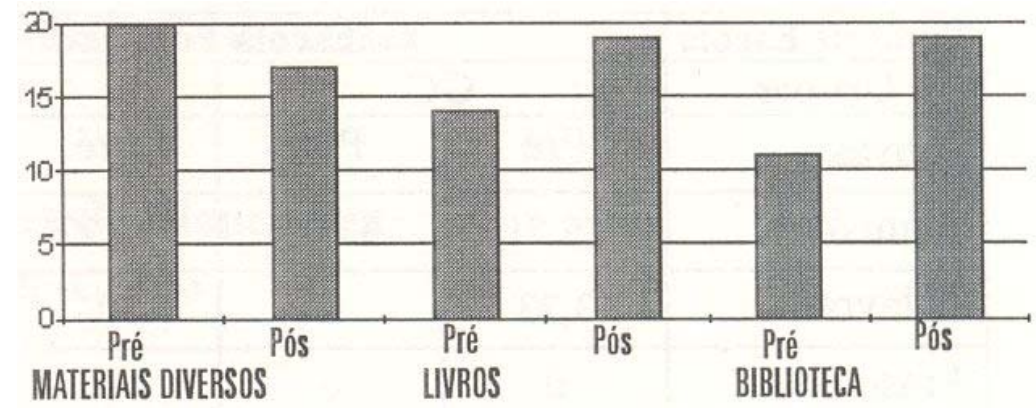

Figura 4. Pontuação atribuída aos sujeitos do grupo experimental (GE) da escola pública relativa ao seu acesso à leitura

Tabela 1 - Porcentagem média das respostas corretas obtidas no Teste Metropolitano de Prontidão (TMP) - Forma R, para os grupos experimental e controle da escola pública e particular ( $\mathrm{n}=9$ )

\begin{tabular}{|c|c|c|c|c|c|c|c|c|c|}
\hline Tipos de Escola & \multicolumn{4}{|c|}{ Escola Pública } & \multicolumn{3}{c|}{ Escola Particular } \\
\hline Grupos & \multicolumn{3}{|c|}{ GC } & \multicolumn{2}{c|}{ GE } & \multicolumn{3}{c|}{ GC } \\
\hline Provas & Pré & Pós & Pré & Pós & Pré & Pós & Pré & Pós \\
\hline Leitura & 72,26 & 78,82 & 66,66 & 81,62 & 90,59 & 90,45 & 92,70 & 91,30 \\
\hline Números & 56,66 & 69,58 & 48,10 & 69,26 & 83,33 & 89,58 & 90,47 & 90,47 \\
\hline Total & 73.50 & 78,70 & 63,45 & 79,38 & 89,50 & 90,50 & 93,14 & 91,28 \\
\hline Classif. & médio & médio & $\begin{array}{c}\text { médio } \\
\text { inferior }\end{array}$ & médio & $\begin{array}{c}\text { médio } \\
\text { superior }\end{array}$ & $\begin{array}{c}\text { médio } \\
\text { superior }\end{array}$ & $\begin{array}{c}\text { médio } \\
\text { superior }\end{array}$ & $\begin{array}{c}\text { médio } \\
\text { superior }\end{array}$ \\
\hline
\end{tabular}

Verifica-se que na classificação geral do teste não houve alteração de nenhum grupo após o programa de leitura, mas observando-se a porcentagem das respostas por prova, nota-se melhora no desempenho para todos os grupos, sendo que há um acréscimo percentual maior no resultado total do grupo experimental da escola pública.

Avaliando-se os resultados do TMP aplicado como forma de acompanhamento do desempenho dos sujeitos, no início da Ia série, de acordo com a Tabela 2, observa-se a manutenção do desempenho anteriormente obtido nos dados apresentados pela Tabela 1.

Tabela 2- Porcentagem das respostas corretas obtidas no Teste Metropolitano de Prontidão (TMP) Forma R, para grupo experimental e de controle da escola pública e particular a nível de acompanhamento dos sujeitos na 1 a série $(\mathrm{n}=9)$

\begin{tabular}{|l|c|c|c|c|}
\hline $\begin{array}{c}\text { Tipo de } \\
\text { Escola }\end{array}$ & \multicolumn{2}{|c|}{ Escola Pública } & \multicolumn{2}{c|}{ Escola Particular } \\
\hline Grupos & GC & GE & GC & GE \\
\hline Leitura & 88,25 & 89,00 & 93,18 & 91,66 \\
\hline Números & 80,20 & 79,16 & 97,90 & 100,00 \\
\hline Total & 87,25 & 87,25 & 94,50 & 94,00 \\
\hline
\end{tabular}

Estabelecendo-se uma relação entre a prontidão dos sujeitos e sua efetiva competência para aquisição da leitura e escrita, os dados da Tabela 3, indicam grandes variações nas porcentagens de acerto dos sujeitos do grupo experimental de ambas as escolas. Após o programa de leitura, sendo que na particular, os sujeitos atingem quase que $100 \%$ de acerto. 
Dessa forma, observamos que a mudança nas atitudes frente à leitura, no maior acesso a livros de histórias, na maior freqüência à biblioteca, na prontidão e competência para aquisição da leitura e escrita, esteve presente nos grupos experimentais das escolas, após o programa, confirmando as pesquisas de McNaunghton (1990) e Combs e Beach (1994).

Quanto ao padrão de interação familiar, não se observaram alterações após o programa de leitura, permanecendo a atividade de assistir televisão e brincar como as mais freqüentes para todos os sujeitos (GE e GC) pesquisados.

De modo geral, segundo a opinião de $90 \%$ dos pais, o programa de leitura foi ótimo por terlhes possibilitado a aprendizagem de novas estratégias para contar histórias, fornecido-lhes informações significativas sobre como propiciar a seus filhos uma leitura mais prazeirosa e informativa, estimulando-os, através das vivências ocorridas, a ler mais freqüentem ente. Através das discussões ocorridas a cada encontro, os pais identificaram situações de aprendizagem que eles podem desenvolver com seus filhos que aliadas às atividades formais da escola garanta-lhes competência geral em suas atividades. Outro fator bastante focalizado pelos pais na avaliação geral do programa foi a importância de melhor conhecerem a escola e sua proposta educacional através de sua presença e participação mais freqüente e ativa dentro da escola, revelando a mesma importância dada por Combs e Beach (1993) à parceria entre família e escola.

Tabela 3 - Porcentagem média das respostas corretas obtidas no ITPA para os grupos experimental e de controle da escola pública e da particular no de pré e pós-testes dos sujeitos na pré-escola

\begin{tabular}{|l|c|c|c|c|c|c|c|c|}
\hline Tipos de Escola & \multicolumn{4}{|c|}{ Escola Pública } & \multicolumn{4}{c|}{ Escola Particular } \\
\hline Grupos & \multicolumn{2}{|c|}{ GC } & \multicolumn{2}{c|}{ GE } & \multicolumn{3}{c|}{ GC } & \multicolumn{2}{c|}{ GE } \\
\hline Provas & Pré & Pós & Pré & Pós & Pré & Pós & Pré & Pós \\
\hline Som/simb. & 29,71 & 37,85 & 32,72 & 67,14 & 44,00 & 100,00 & 51,02 & 100,00 \\
\hline Palavras & 3,23 & 0 & 0 & 47,79 & 0 & 97,14 & 0 & 100,00 \\
\hline Frases & 0 & 0 & 0 & 37,50 & 0 & 96,25 & 0 & 94,31 \\
\hline \multicolumn{1}{|c|}{ Total } & 12,92 & 14,88 & 1286 & 53,08 & 1730 & 09,58 & 2006 & 98,73 \\
\hline
\end{tabular}

Em síntese, essa pesquisa nos mostra a importância de propiciarmos oportunidade de estimular indiretamente a criança através da família para a leitura, pois não somente há mudanças no seu hábito de leitura, mas também seus pais adquiriram novas atitudes frente à leitura para os filhos e aumentaram o tempo de leitura pessoal.

\section{Referências}

Combs, M. \& Beach, J. D. (1994). Stories and story telling: Personalizing the social studies. The Reading Teacher, 47 (6): 464-473.

Dickinson, D. K. \& Smith, M. W. (1994). Long-Term. effects of preschool teachers'book readings on lowincome children's vocabulary and story comprehension. Reading Research Quarterly, 29 (2): 105-122.

Feitelson, D. et alii (1993). Effects of listening to story readining on aspects of literacy acquisition in a diglassie situation Reading Research Quarterly, 28 (1): 70-79.

Handel, R. D. (1992) - The partnership for family reading: beneficts for families and schools. The Reading Teacher, 46 (2): 116-126.

Morrow, L. M. (1994). Family Literary: new Perspectives, new opportunities. IRA. Newark, Delaware

Moura, M. L. S. \& Saboya, M. J. F. (1981). Manual de aplicação do teste de competência em leitura para primeira série. Rio de Janeiro: Fundação Getúlio Vargas. 
Snow, C. E. (1983). Literacy and language: Relationships during the preschool years. Harvard Educational Review, 53: 165-189.

Phillips,G.\& MC NAUGHTON (1990). The practice of storybook reading to preschool children in mainstream New Zealand families. Reading Research Quarterly, 22 (3): 196212.

Rockenbach, M. H. B. C (1990). Contar histórias infantis: o primeiro passo para formar um leitor. Jornal da Alfabetizadora, 2 (10): 7-9.

Santos, A. A. A. \& JOLY M. C. R. A. (1994). Leitura em família: avaliação de um programa com préescolares. XVII Congresso Internacional em Psicologia Escolar / II Congresso Brasileiro de Psicologia Escolar, Campinas: ISPA/ABRAPEE/PUCCAMP.

Santos, P. L. (1993). Representações sobre o comportamento de leitura de crianças e adolescentes - a visão das mães. Dissertação de Mestrado - Programa de Pós-Graduação em Educação - Universidade Federal de São Carlos.

Teale, W. H. (1986). Home background and young children's literacy development. In: W. H. Teale \& E. Sulzby (Eds) Emergent literacy: Writing and Reading. Norwood: Ablex. 